\title{
What are we doing to protect newcomer youth in Canada, and help them succeed?
}

\author{
Brandi Chrismas* and Bob Chrismas*
}

\begin{abstract}
Growing numbers of newcomers and refugees to Canada compel careful consideration to the risks they may be exposed to, including criminal involvement. This paper explores immigrant youths' exposure in their adopted country and the impacts of peer relationships affected by substance abuse, violence, and education in new cultural milieus.
\end{abstract}

Key Words Immigration; refugee; substance abuse; acculturation; assimilation.

Journal of CSWB. 2017 Dec;2(3):87-90

www.journalcswb.ca

\section{INTRODUCTION}

Refugee and immigrant youth often struggle with multiple compounded challenges as they adapt to new cultural milieus, often with completely different social structures and new peer relationships. Their challenges are compounded by language barriers and resulting feelings of marginalization. At the same time, they must often struggle with the stresses of leaving behind their old environments, friends and perhaps families, and cultures. We can examine newcomer integration through a cultural lens because culture encompasses the spectrum of human interaction and societal rules. Avruch (1998) notes that there are 150 or more known definitions of culture. However, an overarching meaning, according to Avruch, is that culture is "a learned shared system of actions, meanings and practices, which are socially and psychologically distributed within a group, and is transmitted laterally and intergenerationally" (p. 17). This helps us frame a way of considering the differences that newcomer youth have to contend with as they move to new countries with unique cultures.

People immigrate to other countries for a variety of reasons, usually in search of a better life. Refugees differ from willing immigrants in that they are forced to seek refuge outside of their country, in order to escape war, or they are in need of protection under international law (MacKay \& Tavares, 2005, p.7). Today, under United Nations (UN) Conventions, refugee status is conferred to individuals who are unable to return to their country of origin, "owing to a well-founded fear of persecution for reason of race, religion, nationality, membership in a particular social group or political opinion" (MacKay \& Tavares, 2005, p.14). Refugees most often have to leave their home, old country and culture in a hurry without bringing their possessions and any important documents, and without saying good-bye to family members. Their occupations and their children's education are likely interrupted. Immigrants, on the other hand, generally have the time to pack personal belongings, gather important documents, and say good-bye, planning to continue all aspects of their lives in their newly adopted country. So, there are some added elements of trauma in the refugee's experience.

There is an economic class of immigration who has "actively sought to settle in Canada including skilled workers, business immigrants and live-in caregivers" and this class makes up the largest portion of immigrants who come to Manitoba (MacKay \& Tavares, 2005, p.14). Family class immigration involves family members who are already established in Canada as permanent residents or citizens, who are sponsoring their relatives entering the country. In doing so, they assume economic responsibility for their sponsored relatives. The different classes of refugee include "Government Assisted and Privately Sponsored Refugees, Refugees Landed in Canada, and Dependents Abroad" (MacKay \& Tavares, 2005, p.14). Despite these definitions, an immigrant may actually have faced refugee experiences but may not qualify as a conventional refugee. Regardless of refugee or immigrant status, transplanted youth face a number of unique challenges, which are affected by the relationships they form in their new environments. Refugee and immigrant youth may be vulnerable to peer influences in their new environments as they struggle to separate themselves from their old cultural identities while trying to fit in and become socialized into a new culture and social environment. This paper explores some of the more unique components of culture and challenges that immigrant and refugee youth face. In particular, it explores immigrant youths' ability to interact with other 
children, and some aspects of peer relationship development in new cultural milieus.

\section{Peer Relationships}

A study by Dipietro and Mcgloin (2012) asked whether or to what extent refugee or immigrant youth are more susceptible to deviant peers and unsupervised socializing with peer relationships. This study incorporated previous research data and observed 1,799 Chicago youths within six cohorts aged 3, 6, 9, 12, 15, and 18 years old. Each subject was interviewed along with his or her primary caregivers up to three times over a five-year period. They concluded that coming into a new social world, these youth value peer acceptance and desire to conform to the normal behaviour. This could motivate them to engage with deviant behaviour, including violence and aggression.

Nonconformity to peer relationships and groups can result in exclusion and ridicule, an outcome teenagers want to avoid at all cost (Dipietro \& Mcgloin, 2012). The study revealed that "spending time with peers in unstructured and unsupervised settings provides [youth] strong situational inducements toward deviant behavior." They further found that delinquency and violent behaviour increased in likelihood under the same circumstances. This confirms conventional parental wisdom about the importance of the friends we choose in our formative years. Refugee or immigrant youth often have added pressures in that they take on adult responsibilities in order to help their parents who may have a language barrier and other transitional challenges; this can limit the youths' opportunities to interact and establish peer relationships. Parents of refugee or immigrant youth may constrain their children from interacting or establishing peer relationships in attempt to preserve their old cultural values and beliefs in their newly adopted cultures. This can create conflicting ideals that affect the youth's social identity among peers. The study by Dipietro and Mcgloin found that immigrant youth may feel greater pressure to fit in, and therefore are at greater risk of conforming to bad behaviour if they fall in with people who are a bad influence.

People operate in multiple social environments. For example, "every person operates in numerous cultural groups, some of which are more significant than others at varied times. The cultures in a person's family, between their friends, in their neighbourhood, their region, their country or even their race, all take on varied significance" (R. Chrismas, Culture and conflict: Cross-cultural perspectives; unpublished paper, University of Manitoba, 2013, p. 4). So, it is important not to homogenize immigrant youth or attempt to look at them as being influenced by only one dimension, such as which friends they choose to spend time with. Their family background and environment, the community they are moving from and into, and the school or workplaces they may be engaged in are all significant influences, as well.

\section{Violence and Aggression}

Dipietro and Mcgloin (2012) conclude that peer relationships are the first attempt of refugee and immigrant youth to define their identity outside of their family, a significant milestone for youth as they are integrating and socializing into a new culture and a new social world. Adolescents experiment with the 'self', and new behaviours and peer relationships, provide context for a developing sense of belonging in their newly adopted culture (Dipietro and Mcgloin, 2012). Defining their identity and seeking a place in a new social milieu, these youth are more susceptible to conform to peer pressure, which might include violence and aggression, depending on what type of friends they fall in with. This again resonates with conventional parental wisdom about the importance of the friends one chooses, especially in the formative teenage years.

Rossiter and Rossiter (2009) explain that other risk factors for violence and aggression may include family, peer, school, and community supports. They found that adolescents who are marginalized may also become alienated and are at higher risk of becoming involved with the criminal justice system. They also stress that visible minorities and immigrants are often depicted in the media as being highly involved in crime. A majority of youth gang members are from visible minorities (about 82\%), are male, and join gangs as young as 13 to 15 years of age (Rossiter \& Rossiter, 2009, p.2). The authors also explain that these young individuals most commonly engage in criminal activities such as drug dealing, property crimes, assault, sexual assault, and homicide.

\section{Substance Abuse}

Research has examined the extent to which identification of one's culture, peer relationships, and coping behaviours affects substance use among refugee or immigrant youth. Lim, Stormshak, \& Falkenstein (2011) assessed psychosocial adjustment to new cultures and correlations with substance abuse among immigrant and refugee youth. In this study, the authors located 102 Cambodian and Vietnamese immigrants, 12-18 years old, adolescent youth, 58 being girls and 44 being boys, in churches, youth groups, and community resource centres in the United States.

They identified four important factors related to substance abuse among these transplanted Cambodian and Vietnamese youth, including: (1) youth cultural identity level, (2) deviant peer association, (3) coping behaviours, (4) and substance use. They explained, "hierarchical multiple regression was used to assess, first, whether being involved in deviant peer association was related to substance use, and, second, whether cultural identification moderated the relationship between deviant peer association and substance use" (Lim et al., 2011). They discovered a relationship between cultural identity, deviant peer association, and substance abuse among the study participants. They found that when identification is high with the culture of origin, substance abuse is lessoned even when they have chosen deviant peers. This shows that a refugee's or immigrant's culture of origin can serve to protect them from the development of substance abuse behaviour. Lim and colleagues found that the influence of deviant peer association and substance abuse may lessen with age.

\section{Education}

According to MacKay and Tavares (2005), a lack of appropriate and specialized programming for adolescent and young adult learners with English as a second language (ESL) needs, especially those from war-affected areas and interrupted schooling backgrounds, exacerbates socio-emotional and learning challenges. In this study, surveys were sent to 
school principals of schools teaching grades seven to twelve, Adult Learning and Literacy Centres. The authors report that the survey questions explored programming and supports, success and challenges, and what programming is further needed for these students. They found that a lack of programming often leads to falling out of the school system and limits the long-term educational and life opportunities of these challenged immigrant learners (MacKay and Tavares, 2005). The authors further explain that the stress and frustration that such learners experience tend to exacerbate the challenges they face integrating into a new society and educational system, thereby contributing to the development of a sense of hopelessness. This finding also resonates with conventional wisdom and common sense, as one would expect newcomers to experience these challenges. It confirms and emphasizes that we, as a society, need to provide resources for immigrant and refugee youth in order to help them succeed.

Some research has examined the pressures that newcomer youth face. Kanu (2008), for example, interviewed refugee youth and many said that they had friends who had succumbed to pressures to drop out of school and join street gangs. Kanu describes in the following passage how the allure of street gangs is too much for many immigrant youth to resist. While the findings are based upon anecdotal accounts, they provide us with important insights into the challenges that newcomers face.

"Despite the academic, economic, and psychosocial challenges faced by the African refugee students in this study, none of them was considering dropping out of school before completing high school. Many of them knew African refugee students who had dropped out because of the "easy money" from gang and drug activities and prostitution, and were now in jail. Without significant help at the levels of both the micro and macro systems, these dropouts are likely to fall into Portes and Zhou's (1993) downward spiral resulting in assimilation into an inner-city underclass" (2008, p. 934).

This social organization that challenges and oppresses youth is an example of structural or invisible violence defined by Galtung (1996), when he first described how social structures can marginalize and disempower certain groups. MacKay and Tavares (2005) concluded from their research that, out of 690 public schools in Manitoba, 400 of them have adolescents that use English as a second language (p.33). In Manitoba, 202,164 adolescents were reported to be enrolled in school systems from kindergarten to grade twelve, and 6,174 adolescents are eligible for ESL support grants (MacKay \& Tavares, 2005, p.33). At the time of their research, school aged newcomers, including refugees, comprised $50 \%$ of all immigrant newcomers to Manitoba (MacKay \& Tavares, 2005, p.33). These statistics are 13 years old, and the massive influx of immigrants has been news headline for much of 2017, indicating that there needs to be further research of this topic. Now, in 2017, Canada has 300,000 new permanent residents each year (Canadian Council for Refugees). It has also been found that a majority of school aged newcomers have significant challenges due to ESL. For example, MacKay and Tavares (2005) state, “The majority of learners identified as presenting significant challenges were those that had ESL needs and interrupted learning, followed by those with ESL needs but without interrupted learning" (p.33).

Several issues can result from adolescents integrating into new schools, including:

"Family struggles to support children in school, literacy issues, poverty, cultural differences and unfamiliarity with the new environment, family stress, trauma from moving and resettlement, students confidence challenged, racism, lack of role models, bicultural, marginalization, slower pace of learning, curriculum and resources may be culturally ethnocentric, teachers lack resources and support to be culturally aware and competent, inadequate support for English as a second language (ESL), separation from family and lack of academic support at home, fear and distrust of authority figures, fast-paced curriculum, acculturation stress and limited human resources for ESL" (MacKay \& Tavares, 2005, p.40).

Given the complex learning needs that refugee and immigrant students may have, only 25\% of schools in Manitoba that reported having refugee students also report having a formal process for screening and identifying refugee learners and their needs (MacKay and Tavares, 2005, p.40). The remaining $75 \%$ of schools in Manitoba indicated having no formal process for screening and identifying refugee learners. It is important to note that schools in Manitoba are not required to screen students for refugee backgrounds or war-affected and disrupted schooling experiences. Learning issues that arise after entry into new schools tend to lead to the identification of refugee or immigrant status (MacKay \& Tavares, 2005 , p. 40). However, Kanu (2008) explains that immigrant and refugee adolescents can find a sense of belonging within school settings.

\section{SUMMARY}

Refugee and immigrant youth want to fit into and be accepted into their new social worlds; they do not want to be seen as different or strange (Kanu, 2008). To "build hope" for refugee and immigrant learners and their families it is critical that schools address their needs more effectively by developing specialized programming and interventions (MacKay \& Tavares, 2005). Experiences in Manitoba and in other jurisdictions suggest that intensive integrated ESL, literacy, and academic preparation, together with career and socio-emotional supports, can be effective (MacKay and Tavares, 2005).

Existing literature suggests that "newcomer" programs (United States), "bridging" programs (Australia), English language development and literacy programs (Canada), and transitional programs and high school-adult programs (Canada) can be quite effective (MacKay \& Tavares, 2005, p.3). Lim et al. (2011) previously found that refugees or immigrant youth have agency and that their choices over acculturation or assimilation are affected by how strongly they identify with their family and the values of their culture of origin. It affects what Lim and colleagues termed "acculturation", in which individuals find a balance between identification with both their culture of origin and their newly adopted one. The authors also reported that "deviant peer association was 
connected with substance use, but identification with culture and coping skills buffered this relationship."

When integrating into new social milieus, immigrant youth generally value being accepted by their peers, and desire to conform to the normal behaviour, which, unfortunately, can include delinquency, violence, and substance abuse if that is normal in the group of friends they happen to fall in with. Berk and Meyers (2016) conclude that these factors are "found less among immigrant youth than peers of the same age groups that are incumbent in the communities they are moving into". This highlights that a refugee or immigrant's culture of origin can play an important role in protecting them from the development of risk behaviour. If a refugee or immigrant youth has low English proficiency, they may experience more difficulty integrating into a new culture.

Immigrant youth may experience more racial and ethnic prejudices and tensions between their family and the new culture they are seeking to join. According to Berk and Meyers (2016), immigrant or refugee youth do eventually become adapted into the new social world and culture, and gain cohesion of family and community. While immigrant youth face many challenges entering Canada, there are many opportunities for Canadian society to adapt and provide the supports these youth need to be successful, happy, and productive. By being sensitive to immigrant youths' needs and placing resources intelligently in order to reduce these challenges, we can ensure that everybody wins.

CONFLICT OF INTEREST DISCLOSURES

The authors declare that they have no conflicts of interest.

AUTHOR AFFILIATIONS

*Faculty of Arts at the University of Manitoba, Winnipeg, MB, Canada.

\section{REFERENCES}

Avruch, K. (1998). Culture and Conflict Resolution. Washington: USIP Press.

Berk, L.E., Meyers, A.B. (2016). Infants and children: Prenatal through middle childhood (8th ed.). Toronto, ON: Pearson Allyn and Bacon.

Canadian Council for Refugees [website]. 2017 immigration levels-comments. Montreal, HQ: CCR. Retrieved from http://ccrweb.ca/ en/2017-immigration-levels-comments

Dipietro, S.M., Mcgloin, J.M. (2012). Differential susceptibility? Immigrant youth and peer influence. Criminology Journal. 50(3), 711-742. doi: 10.1111/j.1745-9125.2012.00273.x. Retrieved from: http://onlinelibrary. wiley.com/woll/doi/10.1111/j.1745-9125.2012.00273.x/full

Galtung, J. (1996). Peace by peaceful means: Peace and conflict, development and civilization. Thousand Oaks, CA: Sage.

Kanu, Y. (2008). Educational needs and barriers for African refugee students in Manitoba. Canadian Journal of Education, 31(4), 915-940.

Lim, M., Stormshak, E.A. \& Falkenstein, C.A. (2011). Psychosocial adjustment and substance use of Cambodian and Vietnamese immigrant youth. Journal of Cross Cultural Psychology, 42(1), 104-119. doi: 10.1177/0022022110362747. Retrieved from: http://journals.sagepub. com/doi/abs/10.1177/0022022110362747

MacKay, T., Tavares, T. (2005). Building hope: Appropriate programming for adolescent and young adult newcomers of war-affected backgrounds and Manitoba Schools. Winnipeg, MB: Manitoba Education, Citizenship and Youth.

Portes, A., Zhou, M. (1993). The new second generation: Segmented assimilation and its variants. The ANNALS of the American Academy of Political and Social Science, 530(1), 74-96. Doi: https://doi. org/10.1177/0002716293530001006

Rossiter, M., Rossiter, K. (2009). Immigrant youth and crime: Stakeholder perspectives on risk and protective factors. PMC Working Paper Series. Edmonton, AB: Prairie Metropolis Centre. 